\title{
Prognostic evaluation model for papillary thyroid cancer: a retrospective study of 660 cases
}

\author{
Yi-Ming Cao ${ }^{1,2 \#}$, Ting-Ting Zhang ${ }^{1,2 \#}$, Bao-Yuan $\mathrm{Li}^{3 \#}$, Ning Qu ${ }^{1,2}$, Yong-Xue Zhu ${ }^{1,2}$ \\ ${ }^{1}$ Department of Head \& Neck Surgery, Fudan University Shanghai Cancer Center, Shanghai, China; ${ }^{2}$ Department of Oncology, Shanghai Medical \\ College, Fudan University, Shanghai, China; ${ }^{3}$ Department of thyroid, the Affiliated Yantai Yuhuangding Hospital of Qingdao University, Yantai, \\ China \\ Contributions: (I) Conception and design: YM Cao; (II) Administrative support: YX Zhu; (III) Provision of study materials or patients: YX Zhu; (IV) \\ Collection and assembly of data: TT Zhang; (V) Data analysis and interpretation: YM Cao, BY Li; (VI) Manuscript writing: All authors; (VII) Final \\ approval of manuscript: All authors. \\ \#These authors contribute equally to this work. \\ Correspondence to: Yong-Xue Zhu. Department of Head \& Neck Surgery, Fudan University Shanghai Cancer Center, Shanghai 200032, China; \\ Department of Oncology, Shanghai Medical College, Fudan University, Shanghai 200032, China. Email: zhuyongxue163@126.com.
}

Background Prognostic evaluation model for papillary thyroid cancer is very important for guiding the personalized treatment and follow-up strategy. There are imperfections in the system existed, and there is no suitable prognostic model for Chinese population.

Methods: This study was based on the clinic and follow-up data of 660 patients received surgical treatments in the Department of Head and Neck Surgery, Fudan University Shanghai Cancer Center from 2000 to 2005. Cox univariate/multivariate analysis was used to explore the influence factors of prognosis, and nomogram model was performed to establish a prognostic prediction system.

Results: Totally, 660 patients for initial treatment were included in our analysis with a median follow-up of 113.5 months. Five-, 10- and 15-year disease-free survival rate was 95.5\%, 90.2\% and 89.2\%. Five-, 10and 15 -year overall survival rate was $99.7 \%, 99.2 \%$ and $99.1 \%$. Residual tumor was associated with overall survival [hazard ratio (HR) 20.9, 95\% confidence interval (CI): 2.3-187.6, $\mathrm{P}<0.05$ ]. Age of onset (HR 2.00, 95\% CI: $1.17-3.42, \mathrm{P}<0.05)$ and the dimension of lymph nodes involved $(0.2-3 \mathrm{~cm}$ : HR 3.67, 95\% CI: $1.13-$ 11.87, $\mathrm{P}<0.05$; $>3 \mathrm{~cm}$ : HR 5.20, 95\% CI: 1.31-20.65, $\mathrm{P}<0.05)$ were independent influence factors of diseasefree survival. The nomogram model for predicting prognosis of papillary thyroid cancer was established with a moderate predictive value (c-index $0.71,95 \%$ CI: $0.57-0.84$ ).

Conclusions: The prognosis of papillary thyroid cancer is very good after appropriate treatment. Age and the dimension of lymph nodes involved were independent influence factors of disease-free survival for papillary thyroid cancer. A prognostic prediction model for Chinese population was established with moderate predictive value. A study with larger samples and including more factors of prognosis is necessary to increase the predictive value of model.

Keywords: Papillary thyroid cancer (PTC); prognostic factors; retrospective study; prognostic prediction model

Submitted Feb 28, 2021. Accepted for publication May 21, 2021.

doi: $10.21037 /$ gs-21-100

View this article at: https://dx.doi.org/10.21037/gs-21-100 


\section{Introduction}

Thyroid cancer is the most prevalent endocrine malignancy in humans. The incidence of thyroid cancer has increased in recent years because of the improving diagnostic approach (1). Papillary thyroid cancer (PTC) is a major type (80-85\%) of thyroid cancer $(2,3)$. The clinical biological behavior of PTC is relatively inert, and the 10-year survival rate can reach more than $90 \%$ after reasonable treatment. However, postoperative recurrence or metastasis cannot be avoided in some patients. It was reported that the 10-year recurrence-free survival rate was only $80 \%$ (4-6). The treatment and management of the increasingly large population of patients with PTC has become a great challenge for oncologists. PTC patients should be divided into different risk groups and got corresponding treatment and management. The staging system is to evaluate the risk of postoperative adverse events, based on the basic information and condition of patients, including age, primary tumor size, cervical lymph node metastasis, distant metastasis, surgical integrity, and tumor staging. The staging system is an important method for evaluating the prognosis of PTC patients and guiding patient management (7). Prognostic prediction is an important part for PTC staging. However, there is no suitable prognostic model for Chinese PTC patients yet. The characteristics of PTC were different between Chinese and Westerners. The incidence of PTC in China is much higher than that in western country. Even immigrants in Western countries have higher rates of disease than the natives. The difference may be related to race $(8,9)$. On the other hand, the therapy of PTC in China was different from that in western. Thyroid lobectomy is more common in China, and isotopic therapy is less common. But in western countries, total thyroidectomy and isotope therapy are more common. Prognosis is bound to vary due to differences in morbidity and treatment modalities for Chinese population. Therefore, it is necessary to establish a separate system for Chinese population. This study was to explore a suitable prediction model for Chinese population based on the clinical and follow-up data of 660 PTC patients from 2000 to 2005 in the Department of Head and Neck Surgery, Fudan University Shanghai Cancer Center. We present the following article in accordance with the STROBE reporting checklist (available at https://dx.doi.org/10.21037/gs-21-100).

\section{Methods}

\section{Samples}

This study retrospectively analyzed the clinical and follow- up data of PTC patients. Patients' basic information, preoperative examination results, surgical records, postoperative histopathological reports, and follow-up records were collected. For PTC is a tumor with excellent prognosis, short time follow-up is not enough to obtain effective statistics. A minimum of 15 years of follow-up is sufficient. Finally, 660 PTC patients were included in our study with a median follow-up of 113.5 months. All of them were initially surgically treated at the Department of Head and Neck Surgery, Fudan University Shanghai Cancer Center (Shanghai, China) from January 2000 to December 2005. Lobectomy and isthmectomy was performed in $\mathrm{T} 1$ and $\mathrm{T} 2$ tumor confined to unilateral lobes. Total thyroidectomy was performed in T3 and T4 tumor or some of the patients with high-risk factors. These risk factors include multifocal cancer, lymph node metastasis, distant metastasis, family history, and early exposure to ionizing radiation. Total thyroidectomy is also feasible in some cases where postoperative radionuclide therapy is considered necessary. Central neck dissection was performed in $\mathrm{cN} 1$ and most of $\mathrm{cN} 0$ patients. Additional modified lateral lymph node dissection was performed in patients with clinically suspicious lateral lymph node metastasis (cN1b). Patients who had undergone previous thyroidectomy or revision neck dissection were excluded. All of the samples were pathologically confirmed. Thyrotrophic (TSH) suppressive therapy was the main treatment after operative. Some advanced PTC (invasive tumors, numerous lymph node metastases, or distant metastases.) were treated with radioactive iodine after total thyroid resection. The study was conducted in accordance with the Declaration of Helsinki (as revised in 2013). The study was approved by ethics board of Fudan University Shanghai Cancer Center (No. 050432-4-1911D) and individual consent for this retrospective analysis was waived.

\section{Follow-up}

During follow-up, neck palpation, ultrasound and thyroid function were performed routinely. Neck computed tomography (CT)/magnetic resonance imaging (MRI) and needle biopsy were performed for patients with suspected neck recurrence. Chest CT, head MRI, bone scan and FDG-positron emission tomography (PET)/CT were used for patients suspected of distant metastasis. Some patients were followed up by telephone/letter in local hospital. Local recurrence, distant metastasis, or death was considered adverse events for disease-free survival (DFS) analysis. 
The diagnosis of local recurrence should be confirmed by pathology. Elevated thyroglobulin without target lesion found by imaging examination (including ultrasound, CT, MRI, PET/CT) after total thyroidectomy was not considered as an adverse event of DFS in this study.

\section{Statistical analysis}

The chi-square test and the $t$-test were used to compare the classified variables and continuous variables in the basic characteristics of patients. Overall survival (OS), and DFS were calculated by Kaplan-Meier method. Univariate analysis was conducted in all possible prognostic factors. Factors that suggested a significant association with prognosis were included in further Cox regression multivariate analysis and nomogram model. The method of building a nomogram model was previously described by Iasonos et al. (10). All confidence intervals (CIs) were stated at the $95 \%$ confidence level. A value of $\mathrm{P}<0.05$ was considered to be statistically significant. SPSS 19.0 was used for data analysis (SPSS, Inc., Chicago, IL, USA). Nomogram model was established using software R 3.3.2.

\section{Results}

\section{Follow-up results}

Totally, 660 PTC patients were enrolled in this study. All of them were initially surgically treated at the Department of Head and Neck Surgery, Fudan University Shanghai Cancer Center (Shanghai, China) from January 2000 to December 2005. The clinicopathological data and followup data of the patients were summarized in Table 1 . There were 486 female and 174 male, median age 44 years (14-83 years). All 660 patients received surgical treatment. Total thyroidectomy and central lymph node dissection were performed in 161 patients. Unilateral thyroidectomy and central lymph node dissection were performed in the other 599 patients. Lateral cervical lymph node dissection was performed in 264 patients. The median follow-up time was 113.5 months. By the end of follow-up, 589 patients had no evidence of metastasis or recurrence. While local recurrence occurred in 8 patients, distant metastasis occurred in 15 patients, and 6 patients died. Of the 14 patients with distant metastasis, 12 had lung metastasis, 1 brain metastasis, 1 bone metastasis, and 1 patient had multiple organ metastases. The 5-, 10- and 15-year DFS were 95.5\%, 90.2\% and $89.2 \%$, respectively. The OS at 5, 10 and 15 years
Table 1 Clinicopathological feature and follow-up outcomes of PTC patients

\begin{tabular}{|c|c|c|}
\hline Variable & Number (n) & Percent (\%) \\
\hline \multicolumn{3}{|l|}{ Gender } \\
\hline Male & 174 & 26.4 \\
\hline Female & 486 & 73.6 \\
\hline \multicolumn{3}{|l|}{ Age } \\
\hline$\leq 45$ years & 351 & 53.2 \\
\hline$>45$ years & 309 & 46.8 \\
\hline \multicolumn{3}{|l|}{ Family history } \\
\hline No & 636 & 96.4 \\
\hline Thyroid cancer & 10 & 1.5 \\
\hline Other malignant tumors & 14 & 2.1 \\
\hline \multicolumn{3}{|l|}{$\mathrm{cN}$ staging } \\
\hline cNO & 416 & 63.0 \\
\hline $\mathrm{cN} 1$ & 244 & 37.0 \\
\hline \multicolumn{3}{|l|}{ Tumor invasion } \\
\hline No & 468 & 70.9 \\
\hline Yes & 192 & 29.1 \\
\hline \multicolumn{3}{|l|}{ Multifocal } \\
\hline No & 536 & 81.2 \\
\hline Yes & 124 & 18.8 \\
\hline \multicolumn{3}{|l|}{ Bilateral } \\
\hline No & 577 & 87.4 \\
\hline Yes & 83 & 12.6 \\
\hline \multicolumn{3}{|l|}{ T staging } \\
\hline $\mathrm{T} 1$ & 381 & 57.7 \\
\hline $\mathrm{T} 2$ & 73 & 11.1 \\
\hline T3 & 78 & 11.8 \\
\hline $\mathrm{T} 4$ & 128 & 19.4 \\
\hline \multicolumn{3}{|l|}{ Total thyroidectomy } \\
\hline Yes & 161 & 24.4 \\
\hline No & 499 & 75.6 \\
\hline \multicolumn{3}{|l|}{ Surgical residue } \\
\hline No & 652 & 98.8 \\
\hline Yes & 8 & 1.2 \\
\hline
\end{tabular}

Table 1 (continued) 
Table 1 (continued)

\begin{tabular}{|c|c|c|}
\hline Variable & Number (n) & Percent (\%) \\
\hline \multicolumn{3}{|c|}{ Lateral cervical lymph node dissection } \\
\hline Yes & 264 & 40.0 \\
\hline No & 396 & 60.0 \\
\hline \multicolumn{3}{|l|}{ Extra-lymph node invasion } \\
\hline No & 586 & 88.8 \\
\hline Yes & 74 & 11.2 \\
\hline \multicolumn{3}{|c|}{ Maximum diameter of metastatic lymph nodes } \\
\hline No lymph node metastasis & 238 & 36.1 \\
\hline$<0.2 \mathrm{~cm}$ & 45 & 6.8 \\
\hline $0.2-3 \mathrm{~cm}$ & 234 & 35.5 \\
\hline$>3 \mathrm{~cm}$ & 69 & 10.5 \\
\hline Unknown & 74 & 11.2 \\
\hline \multicolumn{3}{|c|}{ Number of lymph node metastasis } \\
\hline 0 & 238 & 36.1 \\
\hline $0-4$ & 204 & 30.9 \\
\hline$\geq 5$ & 214 & 32.4 \\
\hline Unknown & 4 & 0.6 \\
\hline \multicolumn{3}{|c|}{ Number of lymph node metastasis in central region } \\
\hline 0 & 313 & 47.4 \\
\hline $0-4$ & 245 & 37.1 \\
\hline$\geq 5$ & 88 & 13.3 \\
\hline Unknown & 14 & 2.1 \\
\hline \multicolumn{3}{|c|}{ Number of lymph node metastasis in lateral region } \\
\hline 0 & 412 & 62.4 \\
\hline $0-4$ & 100 & 15.2 \\
\hline$\geq 5$ & 145 & 22.0 \\
\hline Unknown & 3 & 0.5 \\
\hline \multicolumn{3}{|l|}{ Outcome } \\
\hline Disease-free survival & 589 & 89.2 \\
\hline Local recurrence & 58 & 8.8 \\
\hline Distant metastases & 15 & 2.3 \\
\hline Death & 6 & 0.9 \\
\hline
\end{tabular}

PTC, papillary thyroid cancer. were $99.7 \%, 99.2 \%$ and $99.1 \%$, respectively.

\section{Analysis of prognostic factors}

Prognostic factors of PTC were analyzed. Study factors included gender, age, family history (family history of thyroid cancer or other malignant tumor), the clinical assessment of $\mathrm{T}$ stage, $\mathrm{N}$ stage, tumor invasion, multifocal tumor, bilateral tumor, extra-lymph node invasion, maximum diameter of metastatic lymph nodes, number of lymph node metastasis in central region, number of lymph node metastasis in lateral region, surgical residue, whether total thyroidectomy, whether lateral cervical lymph node dissection, etc. In the univariate analysis about factors affecting OS, only surgical residue was found to significantly affect the survival of patients [hazard ratio (HR) 20.9, 95\% CI: 2.3-187.6, $\mathrm{P}<0.05]$. Other factors were not shown to be associated with patient $\mathrm{OS}(\mathrm{P}>0.05)$. In the univariate analysis about factors influencing DFS, age, $\mathrm{N}$ staging, T staging, lateral cervical lymph node dissection, maximum diameter of metastatic lymph node, number of central lymph node metastasis, number of lateral cervical lymph node metastasis, and total number of lymph node metastasis were all shown to be correlated with DFS $(\mathrm{P}<0.05)$. To analyze the influence of these 8 factors on DFS, Cox multivariate analysis was conducted. The results showed age (HR 2.00, 95\% CI: 1.17-3.42, $\mathrm{P}<0.05$ ) and maximum size of metastatic lymph node (HR 1.75, 95\% CI: $1.12-2.74, \mathrm{P}<0.05)$ were significantly correlated with DFS (Table 2). Patients with age $>45$ had a higher risk of prognostic adverse events (Figure 1). Since the 8th edition of the American Joint Committee on Cancer (AJCC) TNM staging adjusted the age cutoff to 55 years, our subsequent analysis found that patients with $>$ age 55 had a higher risk of DFS adverse events than patients with age $\leq 55$ (HR 2.76, 95\% CI: $1.70-4.50, \mathrm{P}<0.05)$. However, age was not shown to be associated with OS. There was no significant difference in DFS between patients with metastatic lymph node diameter $<0.2 \mathrm{~cm}$ and those without lymph node metastasis. While, the maximal diameter of metastatic lymph nodes between $0.2-3 \mathrm{~cm}$ (HR 3.67, 95\% CI: $1.13-$ 11.87, $\mathrm{P}<0.05)$ and $>3 \mathrm{~cm}$ (HR 5.20, 95\% CI: 1.31-20.65, $\mathrm{P}<0.05$ ) were associated with poor DFS (Figure 2).

\section{Establish prognostic evaluation model of PTC}

Age, $\mathrm{N}$ staging, $\mathrm{T}$ staging, lateral cervical lymph node dissection, maximum diameter of metastatic lymph node, 
Table 2 Cox univariate and multivariate analysis of prognostic factors in PTC patients

\begin{tabular}{|c|c|c|c|c|}
\hline \multirow{2}{*}{ Variable } & \multirow{2}{*}{$\begin{array}{c}\text { Univariate } \\
\text { analysis, } \\
\text { P value }\end{array}$} & \multicolumn{3}{|c|}{ Multivariate analysis } \\
\hline & & $\mathrm{HR}$ & $95 \% \mathrm{Cl}$ & $P$ value \\
\hline Gender & 0.118 & & - & \\
\hline \multicolumn{5}{|l|}{ Male } \\
\hline \multicolumn{5}{|l|}{ Female } \\
\hline Age, years & $<0.05$ & 2.00 & $1.17-3.42$ & $<0.05$ \\
\hline$\leq 45$ & & & - & \\
\hline$>45$ & & 2.00 & $1.17-3.42$ & $<0.05$ \\
\hline$\leq 55$ & & & - & \\
\hline$>55$ & & 2.76 & $1.70-4.50$ & $<0.05$ \\
\hline Family history & 0.997 & & - & \\
\hline \multicolumn{5}{|l|}{ No } \\
\hline \multicolumn{5}{|l|}{ Thyroid cancer } \\
\hline \multicolumn{5}{|c|}{ Other malignant tumors } \\
\hline cN staging & $<0.05$ & 1.13 & $0.46-2.79$ & 0.786 \\
\hline \multicolumn{5}{|l|}{ cNO } \\
\hline \multicolumn{5}{|l|}{$\mathrm{cN} 1$} \\
\hline Tumor invasion & 0.100 & & - & \\
\hline \multicolumn{5}{|l|}{ No } \\
\hline \multicolumn{5}{|l|}{ Yes } \\
\hline Multifocal & 0.138 & & - & \\
\hline \multicolumn{5}{|l|}{ No } \\
\hline \multicolumn{5}{|l|}{ Yes } \\
\hline Bilateral & 0.464 & & - & \\
\hline \multicolumn{5}{|l|}{ No } \\
\hline \multicolumn{5}{|l|}{ Yes } \\
\hline T staging & $<0.05$ & 1.02 & $0.83-1.27$ & 0.827 \\
\hline \multicolumn{5}{|l|}{$\mathrm{T} 1$} \\
\hline \multicolumn{5}{|l|}{$\mathrm{T} 2$} \\
\hline \multicolumn{5}{|l|}{ T3 } \\
\hline \multicolumn{5}{|l|}{$\mathrm{T} 4$} \\
\hline Total thyroidectomy & 0.317 & & - & \\
\hline \multicolumn{5}{|l|}{ Yes } \\
\hline \multicolumn{5}{|l|}{ No } \\
\hline Surgical residue & 0.830 & & - & \\
\hline \multicolumn{5}{|l|}{ No } \\
\hline Yes & & & & \\
\hline
\end{tabular}

Table 2 (continued)
Table 2 (continued)

\begin{tabular}{|c|c|c|c|c|}
\hline \multirow{2}{*}{ Variable } & \multirow{2}{*}{$\begin{array}{l}\text { Univariate } \\
\text { analysis, } \\
P \text { value }\end{array}$} & \multicolumn{3}{|c|}{ Multivariate analysis } \\
\hline & & $\mathrm{HR}$ & $95 \% \mathrm{Cl}$ & $P$ value \\
\hline $\begin{array}{l}\text { Lateral cervical lymph } \\
\text { node dissection }\end{array}$ & $<0.05$ & 1.47 & $0.53-4.07$ & 0.460 \\
\hline \multicolumn{5}{|l|}{ Yes } \\
\hline \multicolumn{5}{|l|}{ No } \\
\hline Extra-lymph node invasion & 0.141 & & - & \\
\hline \multicolumn{5}{|l|}{ No } \\
\hline \multicolumn{5}{|l|}{ Yes } \\
\hline $\begin{array}{l}\text { Maximum diameter of } \\
\text { metastatic lymph nodes }\end{array}$ & $<0.05$ & 1.75 & $1.12-2.74$ & $<0.05$ \\
\hline $\begin{array}{l}\text { No lymph node } \\
\text { metastasis }\end{array}$ & & & - & \\
\hline$<0.2 \mathrm{~cm}$ & & 1.05 & $0.19-5.82$ & 0.959 \\
\hline $0.2-3 \mathrm{~cm}$ & & 3.67 & $1.13-11.87$ & $<0.05$ \\
\hline$>3 \mathrm{~cm}$ & & 5.20 & $1.31-20.65$ & $<0.05$ \\
\hline Unknown & & & - & \\
\hline $\begin{array}{l}\text { Number of lymph node } \\
\text { metastasis }\end{array}$ & $<0.05$ & 0.91 & $0.38-2.19$ & 0.830 \\
\hline \multicolumn{5}{|l|}{0} \\
\hline \multicolumn{5}{|l|}{$0-4$} \\
\hline \multicolumn{5}{|l|}{$\geq 5$} \\
\hline \multicolumn{5}{|l|}{ Unknown } \\
\hline $\begin{array}{l}\text { Number of lymph node } \\
\text { metastasis in central } \\
\text { region }\end{array}$ & $<0.05$ & 1.11 & $0.65-1.90$ & 0.694 \\
\hline \multicolumn{5}{|l|}{0} \\
\hline \multicolumn{5}{|l|}{$0-4$} \\
\hline \multicolumn{5}{|l|}{$\geq 5$} \\
\hline \multicolumn{5}{|l|}{ Unknown } \\
\hline $\begin{array}{l}\text { Number of lymph node } \\
\text { metastasis in lateral region }\end{array}$ & $<0.05$ & 0.72 & $0.38-1.37$ & 0.314 \\
\hline \multicolumn{5}{|l|}{0} \\
\hline \multicolumn{5}{|l|}{$0-4$} \\
\hline \multicolumn{5}{|l|}{$\geq 5$} \\
\hline Unknown & & & & \\
\hline
\end{tabular}

The results were represented as hazard ratio $(\mathrm{HR})$ and its $95 \%$ confidence interval $(\mathrm{Cl})$, where a $\mathrm{P}<0.05$ was considered significant. Sub-variable analyses of age and maximum metastatic lymph node diameter were all based on the data of the first group respectively. PTC, papillary thyroid cancer. 

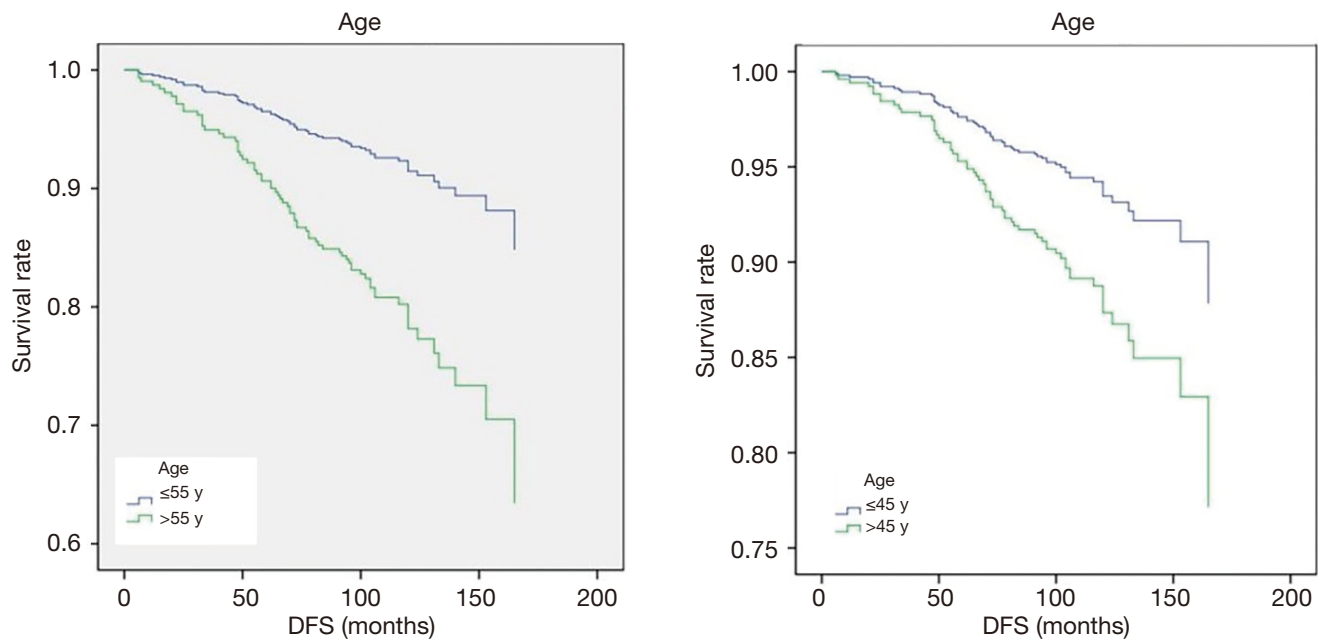

Figure 1 Cox multivariate analysis of DFS and the onset age. DFS, disease-free survival.

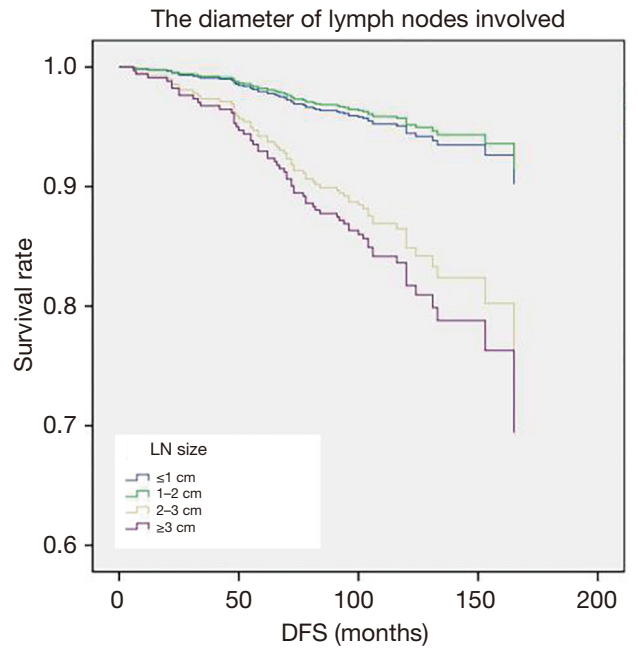

Figure 2 Cox multivariate analysis of DFS and the maximal diameter of metastatic lymph nodes. DFS, disease-free survival.

number of central lymph node metastasis, number of lateral cervical lymph node metastasis, and total number of lymph node metastasis were shown to be correlated with DFS through the univariate Cox analysis. Therefore, these prognostic factors were included in our further nomogram model to predict 3-, 5-, and 10-year DFS (Figure 3). To test the prediction value of the nomogram model, the consistency index (C-index) was further calculated to be 0.71 , with a $95 \%$ CI of $0.57-0.84$. To read the nomogram, a vertical line up to the top point row to assign points for each variable should be drawn. Then, the total points for a patient can be added up, and one can obtain the probability of 3-, 5- and 10-year DFS by drawing a vertical line from the total point's row.

\section{Discussion}

The incidence of PTC is increasing year by year, and the patient population is becoming larger and larger. PTC has a good prognosis and long postoperative survival. But there is still a risk of local recurrence and distant metastasis, which can seriously affect the patient's quality of life $(1,5)$. Therefore, how to give correct and reasonable treatment and how to achieve scientific and individualized postoperative management and follow-up has become the biggest challenge facing thyroid surgeons. The evaluation system is very important for individualized treatment and reasonable follow-up plan. According to the 2012 Chinese and 2015 American Thyroid Association (ATA) guidelines for the diagnosis and treatment of differentiated thyroid cancer, it is recommended to apply the prognosis evaluation system for postoperative stratified management, monitoring the risk of adverse events, predicting the prognosis, guiding postoperative reasonable treatment, and long-term followup $(7,11)$. However, the current PTC prognosis evaluation system was still not ideal, and there was no prognosis evaluation system suitable for the Chinese population. The prognostic factors of PTC still need to be further explored. Through the analysis of clinical and followup data of patients undergoing surgery in our center, the study explored the prognostic factors of PTC, and tried to 


Points
Age
CN
T stage
LLND
LN size
LN number
LLN
CLN
Total points
3-year survival
5-year survival
10-year survival

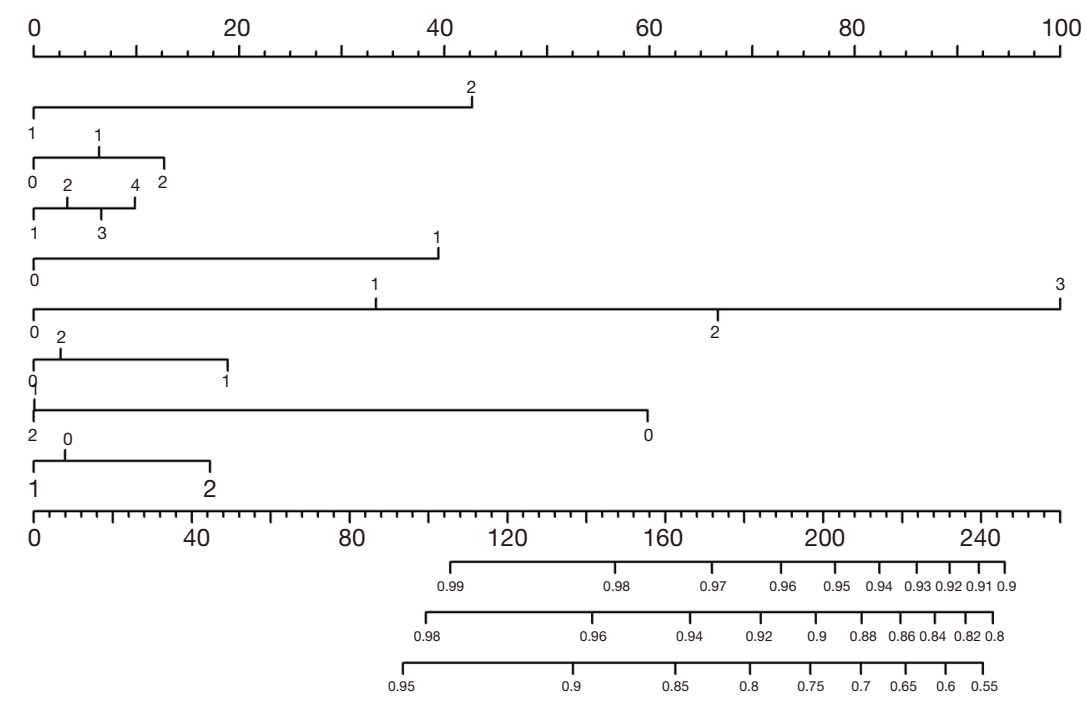

Figure 3 Nomogram model for evaluating prognosis of PTC at 3, 5 and 10 years. PTC, papillary thyroid cancer; LLND, lateral lymph node dissection; LLN, lateral lymph node; CLN, central lymph node.

establish a prognostic evaluation system suitable for Chinese population.

A total of 16 clinicopathological factors were included in this study. Only surgical residue was found to be significantly associated with OS. Since PTC have a good prognosis, local recurrence or distant metastasis of the disease is the biggest problem troubling patients. We performed further Cox regression multivariate analysis and established a nomogram model for the influencing factors of DFS. In Cox multivariate regression analysis, age and maximum size of metastatic lymph nodes were found to be significantly associated with DFS. Patients $>45$ were at greater risk of postoperative DFS-related adverse events than younger patients. Patients were grouped by age 45 years according to the 7th edition of AJCC TNM staging criteria (12). However, the newly released 8th edition of TNM staging criteria for AJCC differentiated thyroid cancer sets the age standard at 55 years. Forty-five years has been the cut-off point for TNM staging of AJCC differentiated thyroid cancer for more than 30 years since the second edition, because the median age of the patient population included in most prognostic assessments is 45 years. However, the cut-off point of 45 was controversial. Some studies suggest that 50-55 was a more appropriate cutoff $(13,14)$. Hay et al. supports the definition of age as 40 years old (15). But the majority of studies were divided into those that supported the age of 55. Thus, the AJCC 8 th edition TNM staging system adjusted the age cut- off point to 55 years. Some studies showed the AJCC 8th edition better differentiated the risk of PTC recurrence for early stages of disease compared with the 7 th edition $(16,17)$. Our results showed age as a prognosis factor both with the cut-off point of 45 (HR 2.00, 95\% CI: 1.17-3.42, $\mathrm{P}<0.05$ ) and 55 (HR 2.76, 95\% CI: 1.70-4.50, $\mathrm{P}<0.05$ ). No much difference was shown between the two cut-off points $(\mathrm{P}>0.05)$. Another independent prognostic factor of PTC is the maximal diameter of metastatic lymph nodes. There was no difference in prognosis between patients with metastatic lymph node diameter $<0.2 \mathrm{~cm}$ and those without lymph node metastasis. Patients with lymph node diameter $0.2-3$ and $>3 \mathrm{~cm}$ had significantly increased risk than those who without lymph node metastasis. In the 2015 ATA differentiated thyroid guidelines, metastatic lymph nodes were divided into high-risk N1 and low-risk N1 groups (7). Low-risk N1 was defined as the number of lymph node metastases $<5$ and the maximum number of lymph node metastases $<0.2 \mathrm{~cm}$. The high-risk N1 include $\mathrm{cN} 1, \mathrm{pN} 1$ with $>5$ lymph node or any of the metastatic lymph nodes were larger than $3 \mathrm{~cm}$. Our study supports that patients with the largest metastatic lymph node of $0.2-3$ or $>3 \mathrm{~cm}$ are at higher risk. In the analysis of the number of metastatic lymph nodes, univariate analysis indicated that the number of central lymph node metastasis, the number of lateral cervical lymph node metastasis and the total number of lymph node metastasis were significantly correlated with DFS. However, there was no significant correlation shown 
in Cox multivariate analysis. The effect of the number of metastatic lymph nodes on the prognosis of PTC still needs further study.

To further explore the influence of various prognostic factors on DFS, we further used nomogram model to establish a patient prognostic evaluation system. To test the prediction value of the nomogram model, the consistency index (C-index) was calculated to be 0.71 (95\% CI: $0.57-$ 0.84 ), suggesting the model has medium predictive value. In order to accurately identify high-risk tumors, several prognostic evaluation systems have been established in these years, like AGES (Age, Grade, Extent of disease, Size), AMES (Age, Metastasis, Extent of disease, Size), MACIS [Metastasis, Age at presentation, Completeness of surgical resection, Invasion (extrathyroidal), Size] and ensemble algorithm of clustering of cancer data (EACCD) $(18,19)$. Most of the evaluation systems were based on western population. And they may not necessarily suit for the Chinese. So, a new system for Chinese is very necessary. But in china, there is no such Public database like Surveillance, Epidemiology, and End Results (SEER). Most study relied on one or few centers. A multicenter database and a larger sample are needed for further improvement.

There are some limitations to the study. Firstly, due to the good prognosis of PTC, few patients have adverse prognostic events, and very few patients die. So, the analysis of relevant survival data needs the support of large sample data and long follow-up term. Finally, a total of 660 PTC patients were included in this study. After a median follow-up of 113.5 months, 71 patients developed DFSrelated adverse event, of which 6 died. Conformance in establishing this nomogram is limited due to the small number of adverse events. And there is not enough data to set up another validation group to validate the model. The lack of external validation reduces the reproducibility and reliability of the model. Secondly, because of the good prognosis of PTC, patients admitted 15 years ago were included in this study to ensure adequate follow-up time. Due to the long follow-up term, there were many limitations in the impact analysis. For example, the medical history system was not perfect and the electronic systems were not yet available at that time. As a result, some data were missing over the years. And the characteristics of PTC had changed a lot from itself 15 years ago. The data shows that the size of PTC and the incidence of lymph node metastasis 15 years ago were much more severe than it is today, because of the lack of early diagnostic method. And even the understanding and treatment of PTC had changed a lot over the 15 years. There were some differences in operative plan between 15 years ago and today. In addition, some prognostic factors confirmed by recent studies (such as BRAFV600E mutation and TERT mutation), were not routinely examined in patients more than 10 years ago. This is an unavoidable limitation due to the rapid academic development. Besides, isotope therapy is an important part of PTC therapy. But detailed isotope therapy data were not available in this study. Because isotope therapy was not available at our center, related data were incomplete and unreliable that we had to abandon it. It is a pity, and it restricts further exploration of prognostic factors in this study.

This study analyzed the data of 660 PTC patients undergoing primary surgery and found that age and maximum metastatic lymph node diameter were independent influencing factors for DFS of PTC. A nomogram prognosis assessment model was established to predicting the prognosis. The establishment of a more accurate prognostic evaluation system for PTC requires prospective multicenter clinical studies with larger samples and more factors.

\section{Acknowledgments}

The authors are grateful to Qing-Hai Ji for kindly providing the administrative supports.

Funding: This work was supported by the Science and Technology Project of Shanghai Science and Technology Committee (grant No. 12ZR1406800), National Science Foundation of China (grant No. 82002827) and Shanghai Sailing Program (grant No. 20YF1438800).

\section{Footnote}

Reporting Checklist: The authors have completed the STROBE reporting checklist. Available at https://dx.doi. org/10.21037/gs-21-100

Data Sharing Statement: Available at https://dx.doi. org/10.21037/gs-21-100

Peer Review File: Available at https://dx.doi.org/10.21037/ gs-21-100

Conflicts of Interest: All authors have completed the ICMJE uniform disclosure form (available at https://dx.doi. org/10.21037/gs-21-100). The authors have no conflicts of 
interest to declare.

Ethical Statement: The authors are accountable for all aspects of the work in ensuring that questions related to the accuracy or integrity of any part of the work are appropriately investigated and resolved. The study was conducted in accordance with the Declaration of Helsinki (as revised in 2013). The study was approved by ethics board of Fudan University Shanghai Cancer Center (No. 050432-41911D) and individual consent for this retrospective analysis was waived.

Open Access Statement: This is an Open Access article distributed in accordance with the Creative Commons Attribution-NonCommercial-NoDerivs 4.0 International License (CC BY-NC-ND 4.0), which permits the noncommercial replication and distribution of the article with the strict proviso that no changes or edits are made and the original work is properly cited (including links to both the formal publication through the relevant DOI and the license). See: https://creativecommons.org/licenses/by-nc-nd/4.0/.

\section{References}

1. Chen $\mathrm{W}$, Zheng R, Baade PD, et al. Cancer statistics in China, 2015. CA Cancer J Clin 2016;66:115-32.

2. Kilfoy BA, Zheng T, Holford TR, et al. International patterns and trends in thyroid cancer incidence, 19732002. Cancer Causes Control 2009;20:525-31.

3. Xiang J, Wu Y, Li DS, et al. New clinical features of thyroid cancer in eastern China. J Visc Surg 2010;147:e53-6.

4. La Vecchia C, Malvezzi M, Bosetti C, et al. Thyroid cancer mortality and incidence: a global overview. Int J Cancer 2015;136:2187-95.

5. Bray F, Ferlay J, Soerjomataram I, et al. Global cancer statistics 2018: GLOBOCAN estimates of incidence and mortality worldwide for 36 cancers in 185 countries. CA Cancer J Clin 2018;68:394-424. Erratum in: CA Cancer J Clin. 2020 Jul;70(4):313. doi: 10.3322/caac.21609. Epub 2020 Apr 6.

6. Hundahl SA, Cady B, Cunningham MP, et al. Initial results from a prospective cohort study of 5583 cases of thyroid carcinoma treated in the united states during 1996. U.S. and German Thyroid Cancer Study Group. An American College of Surgeons Commission on Cancer Patient Care Evaluation study. Cancer 2000;89:202-17.

7. Haugen BR, Alexander EK, Bible KC, et al. 2015 American
Thyroid Association Management Guidelines for Adult Patients with Thyroid Nodules and Differentiated Thyroid Cancer: The American Thyroid Association Guidelines Task Force on Thyroid Nodules and Differentiated Thyroid Cancer. Thyroid 2016;26:1-133.

8. Lee KE, Park YJ, Cho B, et al. Protocol of a thyroid cancer longitudinal study (T-CALOS): a prospective, clinical and epidemiological study in Korea. BMJ Open 2015;5:e07234.

9. Shah BR, Griffiths R, Hall SF. Thyroid cancer incidence among Asian immigrants to Ontario, Canada: A population-based cohort study. Cancer 2017;123:3320-5.

10. Iasonos A, Schrag D, Raj GV, et al. How to build and interpret a nomogram for cancer prognosis. J Clin Oncol 2008;26:1364-70.

11. Chinese Society of Endocrinology, Chinese Medical Association, Chinese Society of Surgery, Chinese Medical Association, Committee of Head and Neck Cancer, China Anti-Cancer Association, et al. Guidelines for the diagnosis and treatment of thyroid nodules and differentiated thyroid cancer. Chinese Journal of Clinical Oncology 2012;39:1249-72.

12. Edge SB, Compton CC. The American Joint Committee on Cancer: the 7th edition of the AJCC cancer staging manual and the future of TNM. Ann Surg Oncol 2010;17:1471-4.

13. Nixon IJ, Kuk D, Wreesmann V, et al. Defining a Valid Age Cutoff in Staging of Well-Differentiated Thyroid Cancer. Ann Surg Oncol 2016;23:410-5.

14. Ito Y, Miyauchi A, Jikuzono T, et al. Risk factors contributing to a poor prognosis of papillary thyroid carcinoma: validity of UICC/AJCC TNM classification and stage grouping. World J Surg 2007;31:838-48.

15. Hay ID, Bergstralh EJ, Goellner JR, et al. Predicting outcome in papillary thyroid carcinoma: development of a reliable prognostic scoring system in a cohort of 1779 patients surgically treated at one institution during 1940 through 1989 . Surgery 1993;114:1050-7; discussion 1057-8.

16. Gan T, Huang B, Chen Q, et al. Risk of Recurrence in Differentiated Thyroid Cancer: A Population-Based Comparison of the 7th and 8th Editions of the American Joint Committee on Cancer Staging Systems. Ann Surg Oncol 2019;26:2703-10.

17. Yang F, Zhong Q, Huang Z, et al. Survival in Papillary Thyroid Microcarcinoma: A Comparative Analysis Between the 7th and 8th Versions of the AJCC/UICC Staging System Based on the SEER Database. Front 
Endocrinol (Lausanne) 2019;10:10.

18. Yang CQ, Gardiner L, Wang H, et al. Creating Prognostic Systems for Well-Differentiated Thyroid Cancer Using Machine Learning. Front Endocrinol (Lausanne)

Cite this article as: Cao YM, Zhang TT, Li BY, Qu N, Zhu YX. Prognostic evaluation model for papillary thyroid cancer: a retrospective study of 660 cases. Gland Surg 2021;10(7):2170-2179. doi: $10.21037 / g s-21-100$
2019;10:288.

19. Konturek A, Barczyński M, Nowak W, et al. Prognostic factors in differentiated thyroid cancer--a 20-year surgical outcome study. Langenbecks Arch Surg 2012;397:809-15. 